\title{
Valor e dinheiro na coleção Sérgio Carvalho: duas abordagens contemporâneas
}

\author{
André Luiz Ribeiro Vitorino ${ }^{1}$
}

Resumo: Este artigo elege quatro conjuntos de obras da Coleção Sérgio Carvalho, unidas pelo suporte comum, o dinheiro, e estabelece uma relação entre essas obras e a produção de Cildo Meireles, tendo em comum o mesmo suporte.

Palavras-chave: Arte Contemporânea brasileira, dinheiro, valor, coleção.

\section{Value and money in Sergio's Carvalho collection: two differents approaches}

Abstract: This article selects four sets of artworks from the Sérgio Carvalho Collection, united by the common support, money, and establishes a relationship between these works and the production of Cildo Meireles, having the same support.

Keywords: Brazilian Contemporary Art, Money, value, collection.

1 Bacharel em Ciência da Computação pela Universidade de Brasília (2002). Bacharel em Teoria, Crítica e História da Arte pela Universidade de Brasília (2018). Atua em Arte Brasileira e Colecionismo. Pesquisador independente em História da Arte - Coleção Sérgio Carvalho. Vínculo institucional: Universidade de Brasília, UnB. E-mail: avitorino@gmail.com. ORCID: https://orcid.org/0000-0001-5884-5290. Lattes iD: http://lattes.cnpq. br/1889648054222519. Brasília, Brasil 
Sediado em Brasília com uma coleção que excede a duas mil obras ${ }^{1}$, o advogado paranaense e colecionador de arte Sérgio Carvalho vem desde o início dos anos 2000 consolidando um rico e plural acervo de arte contemporânea. Dono de um olhar aguçado, o colecionador adquire obras nos mais diferentes formatos, técnicas e temas, sempre séries ou conjuntos de trabalhos de um mesmo artista. Formada em sua maioria por jovens artistas e amigos do colecionador, uma das marcas dessa coleção é a diversidade.

Seu acervo contemporâneo nasce a partir da venda de obras do modernista Oswaldo Goeldi, que Ihe rendeu os recursos para as primeiras aquisições. Eleito como fundador da coleção, Carvalho adquire vários desenhos do amigo e artista Nazareno. ${ }^{2}$

Sem a pretensão de operar como um investidor em arte $^{3}$, a coleção possui uma vocação para trabalhos impactantes e com certa dose de humor ou ironia. O colecionador não comercializa obras, a única venda que admite ter realizado foi a das obras de Goeldi. Sua grande meta, ou, como ele prefere dizer, seu sonho, é, além de consolidar uma amostra significativa da arte produzida no Brasil a partir da década de 2000, disponibilizar toda a coleção para acesso público permanente. ${ }^{4}$

Sérgio Carvalho adquire preferencialmente séries inteiras ou conjuntos de obras que representem aquela produção. De tempos em tempos revisita o artista, mantendo-se atualizado sobre a sua produção e, eventualmente, atualizando também seu acervo. Segundo ele, essa opção acaba por restringir a aquisição de artistas consagrados, pois uma obra não basta e faltam recursos para a aquisição de um conjunto que ele considera adequado $^{5}$. A seu favor, Carvalho conta com um olhar apurado, uma sensibi-

1 Segundo dados coletados com a museóloga que cuida do acervo, sra. Ana Frade.

2 TINOCO, B.; ANGELINI, J. A vertigem do querer de um colecionador voraz: entrevista com Sérgio Carvalho. MODOS. Revista de História da Arte. Campinas, v. 2, n.3, p.261272, set. 2018. p. 267 Disponível em: http://www.publionline.iar.unicamp.br/index. php/mod/article/view/1868; DOI: https://doi.org/10.24978/mod.v2i3.1868

3 CARVALHO, Sérgio. "Coleção de Riscos: Capricho, ilusão e miopia”. In: Catálogo da exposição Cantata, Centro Cultural Minas Tênis Clube. Belo Horizonte-MG. De 10 de jul. a 18 de set. de 2016. p. 6

4 Tinoco, Angelini, 2018, p. 265

5 Tinoco, Angelini, 2018, p. 264 
lidade particular. Ao contrário de outras coleções, no processo de seleção de obras o colecionador conta majoritariamente com sua rede de amigos e seu "gosto" pessoal. $\mathrm{O}$ apoio de redes de galerias, curadores e críticos de arte é secundário.

Dentre toda a pluralidade da coleção, quatro séries de dois artistas diferentes chamam a atenção por terem em comum o dinheiro como suporte. Essas obras operam o dinheiro como símbolo, valor e representação de poder, produzindo diversos entendimentos sobre o mesmo suporte.

Além de nos ocuparmos em observar como essa produção se articula no conjunto da obra desses artistas, entendemos que para compreendê-las é fundamental aproximá-la à obra do artista Cildo Meireles, particularmente seus trabalhos Árvore do dinheiro (1969), Inserções em circuitos ideológicos, Projeto Cédulas (1974-) e Zero Cruzeiro (1974-78) e Zero Dólar (1978-84), que, a partir do dinheiro como suporte, também trabalham sobre a noção de valor, símbolo e circulação. ${ }^{6}$

Produzindo dentro de uma absoluta ausência de uma linguagem formal estabelecida e eclético do ponto de vista do uso de materiais, do tratamento plástico e das mídias empregadas, transitando entre política, arte conceitual e o caráter sensual da arte brasileira pós-neoconcreta, Cildo Meireles possui como uma das questões centrais em sua produção a reflexão sobre a ideia de valor. ${ }^{7}$

Essa reflexão se dá em diversas frentes. O artista abre um campo de investigação muito vasto acerca das escalas dos espaços e dos objetos, bem como da posição relativa do observador em relação a eles. Operando sobre visualidades, formas, pesos e escala, jogando entre o infinitamente grande e o infinitamente pequeno, um jogo de valores se estabelece, às vezes se mostrando claramente quando do uso de dinheiro em seu trabalho. ${ }^{8}$

6 RIVITTI, Thais de Souza. A idéia de circulação na obra de Cildo Meireles. 2007. Dissertação (Mestrado em Artes Plásticas) - Escola de Comunicações e Artes, Universidade de São Paulo, São Paulo, 2007. doi:10.11606/D.27.2007.tde-05072009-212931. Acesso em: 2019-11-14.

7 FERNANDES, João. Cildo Meireles: Guilherme Wisnik, João Fernandes, Sérgio B. Martins. Porto: Fundação Serralves; São Paulo: Cosac Naify, 2013, p. 47

8 Fernandes, 2013, p. 47 
Ao se referir sobre a ideia de valor na sua produção, o artista coloca:

(...) É um tema muito rico, inesgotável. Ouro e paus, por exemplo, tenta trabalhar com limites materiais dos suportes de arte, desde madeira mais barata até o ouro. Em Fontes trato mais da questão do indivíduo no universo, é a materialização do número, a construção mais abstrata que existe. (...) Na instalação Fontes, que mostrei na Documenta (Kassel, Alemanha, 1992), há a sensação de isolamento absoluto do indivíduo, número entre números. ${ }^{9}$

Já o dinheiro também aparece de forma destacada na sua produção. Prosseguindo nas palavras do artista:

O dinheiro é um elemento recorrente no meu trabalho e adota diferentes funções: em Árvore do dinheiro aponta para a questão do valor do objeto de arte e a defasagem entre valor de uso e valor de troca. Associa-se metaforicamente a Eureka, ao conceito de densidade: o que é e o que parece ser. Os Zeros (Zero cruzeiro e zero centavo, 1974-78) são uma demonstração da Árvore do dinheiro. Essa ambiguidade de ser matéria e símbolo (no caso do Brasil, o dinheiro foi em dada época o material mais barato). Em Inserções... ou Eppur si muove (1991) está o problema da circulação. E em Missão/Missões (1987) aparece como material antigo, ancestral.10

Em seu primeiro trabalho se utilizando de dinheiro, Árvore do dinheiro (1969), Cildo Meireles vai diretamente ao ponto e aborda a questão da dubiedade do dinheiro, seu uso como matéria prima e símbolo, a partir de um objeto de arte. $^{11}$

Cem notas de um cruzeiro dobradas ao meio amarradas com um elástico de borracha, desses tipicamente utilizados em bancos, e apresentadas em uma base de madeira, à maneira de um pedestal. Esse pedestal de madeira, além de elevar o maço de dinheiro à categoria de objeto de culto, de apreciação e reverência, estabelece uma relação direta com o nome da obra, referenciado a mítica árvore do dinheiro, fonte inesgotável de renda. ${ }^{12}$

A obra ainda possui uma legenda onde se lê: "100 notas de 1 cruzeiro novo. Preço: 2 mil cruzeiros". ${ }^{13}$

9 MORAES, Angélica. Criação de Valor. In: O valor da obra de arte. Metalivros SP Produção e Comunicação Ltda. (Metalivros), 2014. São Paulo p. 120

10 Fernandes, 2013 p. 110

11 SCOVINO, Felipe (org.) Encontros / Cildo Meireles. Rio de Janeiro: Azougue Editorial, 2009. Escritos do artista e depoimentos / Artist's Writings, and statements p. 252

12 Riviti, 2007, p. 47

13 A obra possui versões com notas de um $\mathrm{Cr} \$ 1,00$ e notas de $\mathrm{Cr} \$ 1.000,00$ carimbadas 
Essa primeira inserção do dinheiro na obra de Cildo Meireles, para além do artista sob a perspectiva Duchampeana, tensiona o valor de face do dinheiro, não apenas comuta objetos do cotidiano em objetos de arte, ele opera diretamente entre a matéria prima e o símbolo, valor simbólico e valor real das coisas, valor de troca e valor de uso. ${ }^{14}$. Afinal, quem sustenta o valor do dinheiro? Como ele é dado e como pode ser subvertido?

Nesse movimento, o artista retira o dinheiro do seu circuito social e econômico, aprisiona-o num pedestal, o que supostamente aumentaria seu valor, numa operação contraditória e até paradoxal. Aquele que seria o fruto da árvore do dinheiro não pode ser usado para o consumo. Imobilizado num pedestal ele vale mais, mas somente quando fora de seu uso primeiro.

Penso que, de certa maneira, ele enxugava toda a série de manchas nessa ideia de pontar um paradoxo: valor simbólico e valor real das coisas. É uma obra que fica entre a ficção e a realidade. 15

Apesar de ser uma continuidade deste trabalho, a retirada do dinheiro de seu circuito de circulação contrasta frontalmente com o trabalho Inserção em circuitos ideológicos, projeto cédula, 197016, no qual cédulas são carimbadas e reinseridas no sistema de circulação, tornando-se hospedeiras para mensagens de cunho político e subversivo.

O trabalho Inserção em circuitos ideológicos foi iniciado por Cildo Meireles em 1970. A primeira parte do trabalho, chamado Projeto Coca-Cola, consistiu na inscrição de frases em vasilhames de Coca-Cola que seriam devolvidos à circulação. As frases foram decalcadas e, com o vasilhame vazio eram praticamente imperceptíveis, porém, quando a garrafa era novamente preenchida o texto tornava-se aparente.17

No segundo projeto do trabalho, Projeto cédula (1970), foram carimbadas as seguintes frases: "yankees go home!", "Wich is the place of the work of

com o valor de $\operatorname{Cr} \$ 1,00$, em decorrência da introdução do cruzeiro novo no ano de 1967.

14 Scovino, 2009

15 Scovino, 2009

16 O Projeto cédula não possui um fim determinado.

17 Rivitti, 2007, p. 35 
art?", "QUEM MATOU HERZOG?". Esse trabalho não possui um fim determinado, e, esse procedimento prossegue sendo executado ainda em 2014, com inscrições do tipo "Cadê Amarildo?", em referência ao ajudante de pedreiro analfabeto e morador da favela da Rocinha torturado e morto por policiais em sua própria comunidade.

A escolha do dinheiro como suporte (quando comparados às garrafas de Coca-Cola) aprofunda a dissolução do trabalho na circulação social. O hábito de escrever em cédulas de dinheiro tais como jogos, frases jocosas, piadas, correntes e ditos populares já eram prática comum no Brasil. O que o artista faz é apropriar-se desse circuito, inserindo seus comentários em meio às mensagens anônimas18.

Sob a perspectiva da circulação, diferentemente do Projeto Coca-Cola, as mensagens parasitam um sistema oficial, uma instituição que está nas entranhas dos sistemas de governo e de mercado, um parasitismo que afeta sistemas oficiais e formais de governo, estruturas legalmente constituídas das quais dependem os sistemas do Estado.

Destaca-se também nesses trabalhos a instauração de uma nova relação com o público. Para essa geração de artistas a participação popular era central e o artista almejava retirar o público de um estado de alienação. A geração de Meireles incorpora criticamente a noção de participação. Aqui o público é a massa, homogeneizada, dispersa, eminentemente voltada para o consumo. A ideia de participação mostra-se encoberta por mecanismos de ação e reação, automáticos, dentro da lógica do consumo que se queria evitar19.

Sobre a questão da ideologia presente no hospedeiro desse sistema, fazendo referência às notas do crítico Ronaldo Brito, a pesquisadora Thaís de Souza Rivitti coloca:

Alguns críticos, como Ronaldo Brito, chamaram a atenção para o procedimento da inserção que consistiria em utilizar-se de objetos fabricados, muito marcados por sua circulação social, e colocar neles um corpo estranho, invertendo assim o sinal de sua "mensagem". Essa leitura diz que os circuitos veiculam apenas a sua própria ideologia, mas que, também, são passíveis de receber inserções capazes de contradizê-la. A 
inserção, ao mesmo tempo, funcionaria como uma explicitação do discurso original veiculado pelo objeto coca-cola, discurso que permanecia oculto. Ou seja, as garrafas de refrigerante, mesmo antes da inserção, não eram simplesmente meros recipientes, mas celebravam a cultura norte-americana, propagavam um estilo de vida. Mas é com a inserção, que marca posição contrária a isso tudo, que seu discurso original aparece. O procedimento crítico da obra consistiria também em revelar a carga ideológica dos produtos consumidos cotidianamente. 20

Apesar de se referir ao primeiro Projeto Coca-Cola, a reflexão se aplica diretamente ao projeto Cédula, que também carrega um poderoso discurso de poder, que pouco percebemos no dia a dia.

Zero cruzeiro (1974-78) e Zero dólar (1978-84) nascem do trabalho Árvore do dinheiro 21 . Nesse trabalho são produzidas notas de valor de face zero cruzeiro e zero dólar. Nas cédulas de zero dólar os vultos históricos foram substituídos pelas figuras do Tio Sam e do Fort Knox. Essas notas foram produzidas em grande quantidade, inicialmente 10.000 cédulas distribuídas na $\vee$ Bienal de Sidney (Austrália, 1984) e, posteriormente, mais 10.000 que foram distribuídas pelo artista.22

Já nas cédulas de Zero Cruzeiro produzidas, o procedimento do artista contou com um lastro mais histórico e pessoal. $\mathrm{O}$ artista conta como definiu as imagens que figurariam nas notas:

Com relação à imagem do índio que aparece no verso das notas, eu tinha relido um dossiê que o meu pai deixou sobre o massacre dos krahôs, no Bico do Papagaio, uma região situada entre os estados de Goiás, Pará e Maranhão. Aquele pedaço de terra era muito cobiçado. Nesse dossiê consta o primeiro telegrama, reportando esse massacre, escrito por um pastor maranhense para o Serviço de Proteção aos Índios. Por conta disso, meu pai foi mandado para investigar e acabou descobrindo que não houve um massacre, mas dois. Ele se envolveu nessa causa e, de certa maneira, isso custou sua carreira.

Ainda nesse dossiê, consta que um fazendeiro, nos anos 1930, ordenou o primeiro massacre contra esse grupo de índios, os krahôs. O massacre foi realizado através de um avião monomotor que sobrevoou a região e jogou roupas infectadas com vírus da gripe e bacilos de Koch. Quinze dias depois, os 4 mil índios se transformaram em quatrocentos, dos quais duzentos ficaram enlouquecidos, por que haviam perdido tudo: família, vínculo e vida identitária.

(...)

Com relação à imagem do louco que aparece no verso das notas, havia uma espécie

20 Rivitti, 2007, p. 41

21 Moraes, 2014, pp. 111-112

22 Moraes, 2014, p. 112 
de manicômio em Goiás que me chamou a atenção. Eu queria fazer uma série de entrevistas naquele lugar e registros fotográficos.

(...)

Depois de ter feito os registros fotográficos, reparei que em vários deles havia sempre a presença de uma figura ao longe, às vezes de lado, com a cabeça abaixada, escondida entre os braços, que eu não tinha fotografado diretamente. Quando voltei ao hospital eu perguntei à diretora, que era uma freira: "Quem é esse? A senhora nunca me falou dele em nossas conversas". Ela respondeu: "Esse senhor chegou há 17 anos. Foi para esse pátio, estabeleceu-se nesse canto e ali ficou. Desde então, ele acorda, vai pra lá e passa o dia inteiro com a cabeça assim". Ele tinha uma culpa terrível, ficava encarando aquele canto para sempre. Eu uso nos trabalhos uma foto de lado e outra de costas desse homem. ${ }^{23}$

Para além de um instrumento bem adaptado às necessidades econômicas e financeiras das sociedades, o dinheiro tornou-se também um suporte e veículo de expressão identitária, política, religiosa, ideológica e um poderoso instrumento de propaganda ao dispor dos Estados. 24
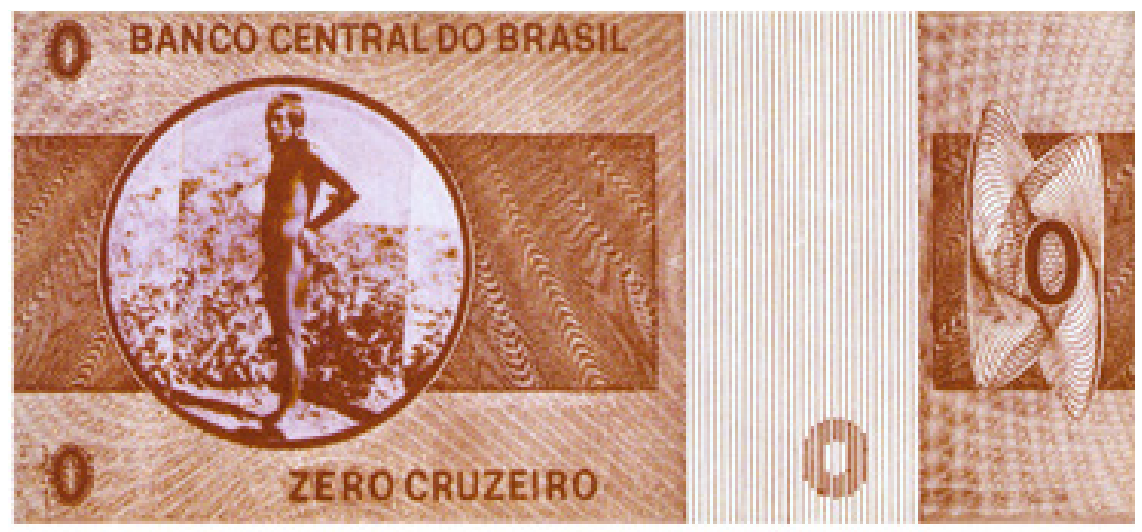

Figura 1

Cildo Meireles

Zero Cruzeiro, 1978

Lito offset sobre papel moeda. Fotografia: lara Venanzi/
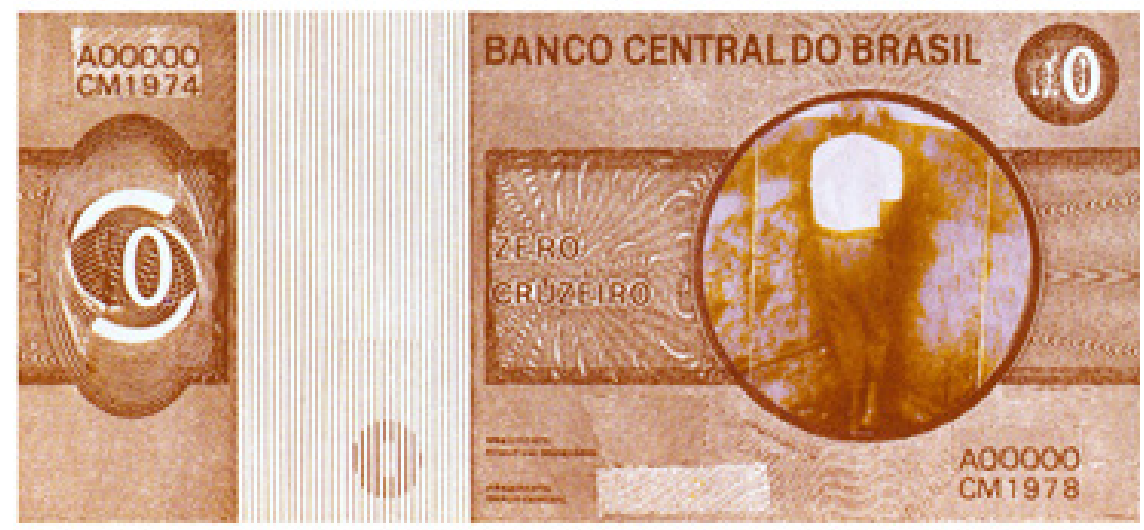

Itaú Cultural

24 VIEIRA,João Pedro. A história do dinheiro. Academia de Ciências de Lisboa. Lisboa, 2017. ISBN 978-972-623-328-2, p. 10 
A tradição de estampar em suas cédulas e moedas retratos de governantes e soberanos, remonta à $1^{\text {a }}$ metade do século IV a.C., sobretudo com os sucessores de Alexandre III da Macedônia. A partir do século I a.C., no final do período republicano romano, vários líderes militares se fazem representar ou são representados em moedas através de seus retratos, dando especial continuidade ao aproveitamento propagandístico da moeda. A partir de Augusto, o elemento dominante na iconografia monetária passa a ser dos imperadores, com múltiplos casos de extensas titulaturas imperiais rodeando o retrato soberano dos imperadores. 25

A manobra de Cildo Meireles dá uma nova roupagem a essa tradição milenar, substituindo o vulto da personalidade notável pelo dejeto social, estampando o anverso e o reverso de sua cédula de Zero Cruzeiro de forma condizente com o valor de face da cédula. Duas situações existenciais e políticas marginalizadas, confinadas em territoriedades delimitadas, reserva indígena e instituição psiquiátrica.26

Dentre as diversas questões suscitadas pelo trabalho, Cildo Meireles faz um apontamento relevante sobre a operação com notas de dólares além das notas de cruzeiro. Segundo ele, o objetivo é que sua crítica não fosse confundida com um comentário ou uma crítica à inflação, ou seja, regionalizar, localizar e limitar a sua ação. O que o interessava era discutir o espaço entre valor simbólico e valor real, valor de uso e valor de troca, não a situação particular de inflação do país27. Essa reflexão se aplica tanto ao trabalho dos Zeros quanto à Árvore do dinheiro.

João Angelini é um jovem artista de Brasília. Tendo na imagem em movimento o maior ponto de partida para suas pesquisas, seu trabalho desdobra em vídeos, performances, instalações e objetos.

Atento às estruturas sociais e com foco no cotidiano, a produção do artista também opera sobre a questão do valor, seja do trabalho inútil, repetiti-

25 Vieira, 2017, p. 10

26 HERKENROFF, Paulo, Arte é Money. In: MOSTRA DA GRAVURA CIDADE DE CURITIBA, 11., 31 de outubro a 29 de dezembro de 1995, Curitiba, PR. XI Mostra da Gravura Cidade de Curitiba: 31 de outubro a 29 de dezembro de 1995. Curitiba: Fundação Cultural de Curitiba, 1995. p. 76

27 Scovino, 2009, p. 256 
vo e alienado, como nas animações L.E.R. (2007) e De Castigo (2012), também no acervo de Carvalho, seja de uma forma mais direta, operando sobre o dinheiro como valor estabelecido pelo cotidiano.

Com 24 obras no acervo de Sérgio Carvalho (mais outras três obras juntamente com o Grupo EmpreZa, incluindo uma performance), duas séries do artista aderem à nossa proposta de investigação28.

A primeira série, dos Reais furados, é composta de sete dípticos cada um composto de uma cédula de Real (um real, dois reais, cinco reais, dez reais, vinte reais, cinquenta reais e cem reais), recortadas a laser como um quebra-cabeças. Deste quebra-cabeças, que permanece montado, apenas uma das peças foi retirada de cada nota e colocada em uma moldura idêntica compondo o díptico.

A obra está emoldurada (assim foi entregue pelo artista) numa espécie de sanduíche de vidro com bordas profundas de madeira, de forma que possa ser exposta de qualquer um dos lados ou mesmo os dois lados ao mesmo tempo. Na mostra Contraponto29 a curadoria optou por apresentá-las com o anverso para o espectador para as cédulas de um, dois, cinco, dez e cinquenta reais e pelo reverso nas demais cédulas.

A peça retirada corresponde sempre aos olhos da Efígie da República (os recortes não são precisamente os mesmos em todas as cédulas da série apesar de bastante próximos) e sobre essa parte retirada o artista executa um procedimento diferente em cada nota da série.

Esse procedimento consiste na dilaceração e na posterior reconstrução da peça, sempre de forma grosseira e rude, trazendo um componente de precariedade, de imperfeição, de insuficiência. Na cédula de um real o fragmento retirado foi recortado e costurado, com linha preta. Já na cédula de dois reais, a peça é recortada em traços retos, embaralhada e reagrupada

28 Além das duas séries presentes na coleção, o artista ainda desenvolveu outros trabalhos se utilizando de cédulas e moedas como suporte. Essas obras não serão abordadas pois não pertencem ao acervo do colecionador Sérgio Carvalho.

29 De 17 de novembro de 2017 a 29 de abril de 2018, no Museu Nacional do Conjunto Cultura da República, em Brasília, a curadora Tereza de Arruda apresentou a mostra Contraponto, com obras da Coleção Sérgio Carvalho. Essa mostra contou com 430 trabalhos de 34 artistas e coletivos. 
com fita do tipo durex. Na de cinco, foi grampeado diversas vezes num emaranhado de grampos, tortos e sobrepostos. Na nota de dez reais o pedaço retirado foi chamuscado, suas bordas estão carbonizadas e a peça levemente enegrecida. Na cédula de vinte reais a peça retirada foi novamente recortada e reagrupada com fita do tipo durex, criando um emaranhado espesso que lembra aqueles maços de moedas agrupados com fita. $\mathrm{Na}$ nota de cinquenta o componente removido foi novamente grampeado grosseiramente. Por fim, o fragmento da cédula de cem reais foi costurado sem cuidado com uma linha branca.

No reverso das notas o pedaço extraído sempre está posicionado sobre o animal da fauna brasileira representado na nota, extraindo-lhes um pedaço.

Se por um lado a colocação da obra numa moldura elimina o valor de compra daquelas cédulas, o procedimento do artista estabelece a ela um novo valor, substancialmente maior que seu valor de face. Assim como no procedimento de Cildo Meireles ao colocar seu maço de dinheiro sobre um pedestal, Angelini atribui um novo valor às cédulas operadas.

Ainda amparados nas proposições de Cildo Meireles para seus trabalhos, rejeitaremos aqui a solução mais imediata e simples, de que a obra se trate de uma representação de um sistema inflacionário, que corrói e desvaloriza o dinheiro.

O trabalho introduz elementos que se desdobram em múltiplos entendimentos, e, observando a série completa vemos que o artista utilizou de soluções distintas, mas que convergem num discurso comum um pouco mais complexo.

Elemento central na obra, os "remendos" dos fragmentos retirados são realizados de forma grosseira e com materiais do cotidiano, que lembram formas fáceis de se remendar, disponíveis no dia a dia, em casa, no escritório, nas repartições e que, por vezes, são utilizados tanto para "remendar" notas velhas quanto para reparar objetos ordinários, sem apreço pelo acabamento ou pela solução final. São soluções dadas por uma camada mais pobre da população brasileira para seus problemas corriqueiros, como o troco do ônibus que se parte, a roupa velha que se rasga, a estrutura dos óculos que não se sustenta mais, o cabo do carregador de celular que está prestes a se partir. Seria aquele fragmento a parte que lhes cabe?

Essa crítica social, representada por um, apenas um fragmento, essa parte 
do dinheiro, da riqueza nacional, essa fração tão pequena, oferecida aos miseráveis parece ser a crítica contundente dessa obra. Não a corrosão pela inflação, mas o resíduo que sobra, a menor fatia, e, como se seu tamanho não bastasse, ainda se encontra e remendada, chamuscada, danificada e precariamente reconstruída, semelhante às políticas públicas implementadas pelo nosso Estado. Aparenta estar destacada e protegida, mas na realidade compõe-se de um remendo, a pior parte de uma manobra grosseira sem disfarces.

Assim como no trabalho de Cildo Meireles, na segunda série do artista João Angelini, Novo Bloco Econômico Ocidental (2012-17), o artista introduz cédulas de dinheiro estrangeiro, dólar e euro, numa composição com o dinheiro nacional, remontados como peças de um quebra-cabeças que procuram reconstituir, de forma grosseira uma cédula funcional.

Cada obra se constitui de um tríptico, sendo cada unidade a junção de fragmentos das três notas recortadas. O acervo conta com o conjunto formado por cédulas de cinco, dez, vinte, cinquenta e cem unidades monetárias.

Desenvolvida a partir de 2012, quando o país gozava de uma economia mais estável e estabelecia-se como parceiro comercial de relevância tanto para os Estados Unidos quanto para a Europa, o artista antecipa na obra a fragilidade dessa junção entre parceiros tão distantes economicamente (com cédulas fortes e o dinheiro brasileiro), como se quisesse dizer: É claro que isso não vai dar certo!

Dos arranjos sobram fragmentos que são colocados ao lado, mostrando claramente que dali sobraram peças, há uma incompletude e ao mesmo tempo um resto, uma sobra que não foi contemplada, que não conseguiu se inserir nessa nova composição.

Curiosamente, e ao contrário da primeira série, essas obras não foram entregues ao colecionador emolduradas, seus pedaços são "soltos", podem se perder, fazendo parte do trabalho a precariedade tanto da montagem quanto dos blocos que ali são representados.

Se por um lado essas cédulas são tratadas da mesma forma, possuem o mesmo valor de face e são visualmente equivalentes, sabemos que existe uma distinção de valor forte sobre elas. É no alinhamento no valor de face, na colocação lado a lado, em pé de igualdade entre os dinheiros, onde reside a ironia desse frágil arranjo que se desmancha já na entrega. O arranjo 
apresentado toca a mesma questão apresentada por Cildo Meireles, entre valor de face e valor real, desta vez sob uma perspectiva de globalização, uma perspectiva altamente contemporânea.

O jovem carioca Rodrigo Torres também opera sobre uma larga faixa de suportes e técnicas. Atualmente com 35 trabalhos na coleção, esses se dividem em intervenções bem-humoradas sobre revistas, três obras da série Encapetadas (2009) e um trabalho da série Pavê (2009), fotografias em montagem topográfica ( 5 obras sem título e sem vinculações a séries), e mais 31 obras construídas a partir de cédulas de dinheiro.

Vamos nos deter nessas duas séries delas, 27 trabalhos da série Uns tro-

Figura 2 Oc\$50,00, João Angelini. Da série Novo Bloco Econômico Ocidental, 2012/2017 Cédulas de euro, dólar e real sobre papel cortadas a laser $60 \times 40$ $\mathrm{cm}$ (tríptico) Fotografia: Catálogo da exposição Contraponto/Ding Musa cados (2010) e o políptico composto por quatro obras Camafeu e grade (2011), elegíveis segundo o nosso critério.

Os trabalhos da série Uns Trocados (2010), constituem-se de construções, cenários, paisagens, ou mesmo montagens semelhantes a cédulas a partir de fragmentos de cédulas, imagens recortadas e agrupadas formando novas imagens. Com refinado preciosismo técnico, os recortes são realizados com estiletes remontando ao procedimento inicial das gravuras, a incisão na matriz realizada manualmente com instrumento pontiagudo.

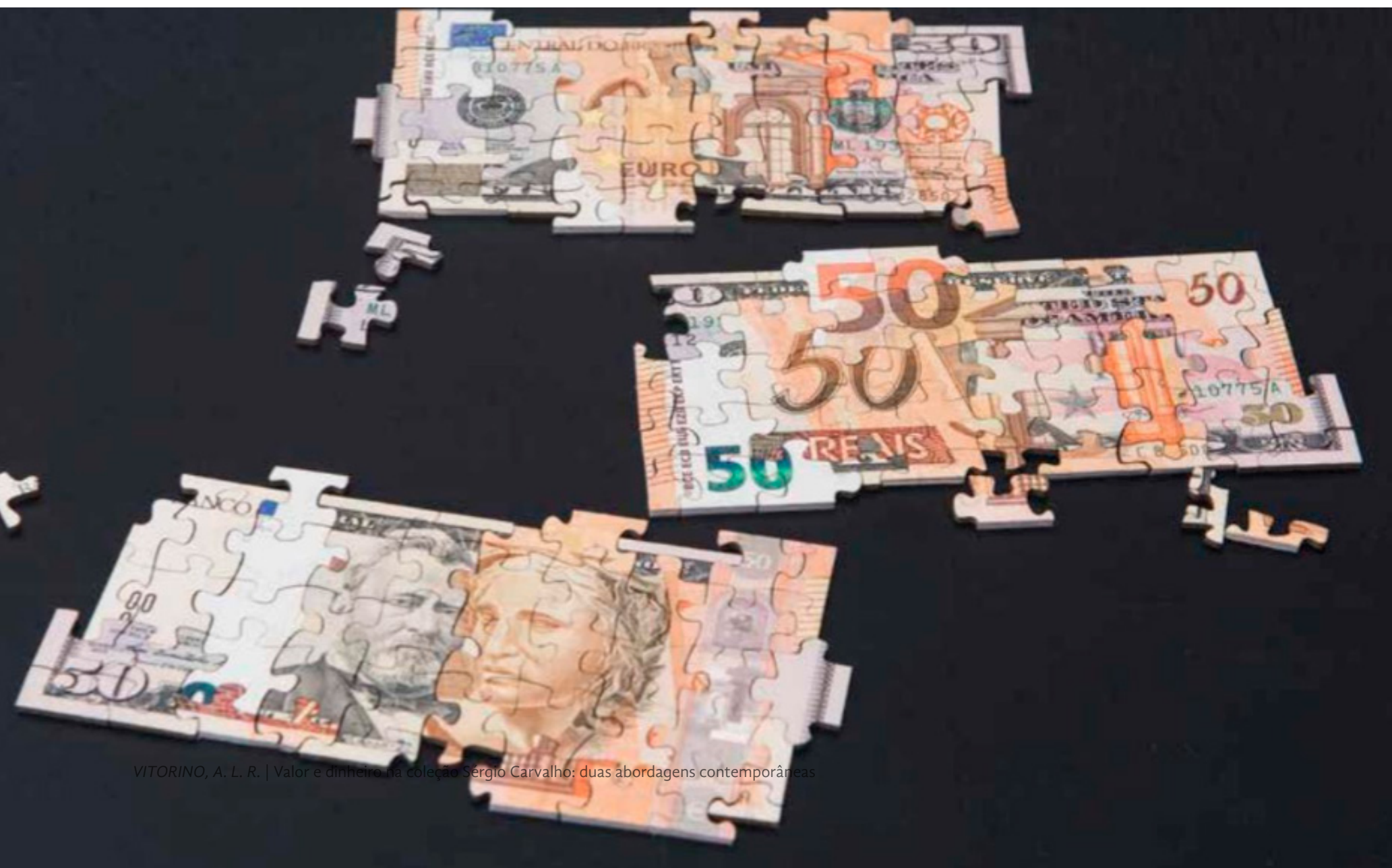


São utilizadas cédulas de dinheiros de mais diversos países e valores misturados uns aos outros, formando dois ou mais planos, dando uma ideia de tridimensionalidade nas obras. Há a preocupação do artista em manter elementos que denunciem a matéria prima do trabalho. Por vezes são deixadas inscrições como Bank of Ghana, ou Banco Central del Ururuay, Cien Pesos Bolivianos, porém, noutras são deixados apenas elementos decorativos, molduras, arabescos e números, que, apenas para o olhar mais atento, denunciam o material que originou aqueles recortes.

Apesar da aparente destituição do valor do dinheiro, o símbolo que ele carrega não deixa de denunciar um símbolo de poder. $\mathrm{O}$ artista o coloca em cheque quando opta por deixá-lo transparecer, mas o utiliza apenas como fonte de elementos decorativos, mais presentes no trabalho. As personalidades representadas não mantêm seus status ou seus títulos, nota-se inclusive a utilização de cédulas produzidas para fins recreativos e paralelos, como uma nota de um Disney Dollar figurando um pirata em sua efígie (sob a moldura de uma cédula de dez cruzeiros).

Como são utilizados fragmentos de cédulas de diversas moedas do mundo, seu valor não pode ser computado, eliminando seu valor de troca e convertendo as cédulas em fontes de recortes de elementos decorativos.

Como a curadora de uma das grandes exposições do acervo de Sérgio Carvalho, Marília Panitz, diz, esse trabalho de Rodrigo Torres revela um "tesouro obtido a partir da destruição do poder de compra"30

O políptico Camafeu e grade (2011), pertencente ao acervo, também se constitui de colagens resultantes da remoção das imagens presentes na série de cédulas de Cruzeiro emitidas a partir de 1942 e em circulação até 1975. Essa série, emitida durante o governo de Getúlio Vargas, foi a primeira série de Cruzeiros (em substituição aos Réis ainda do império), sendo "carimbada" em 1967 durante o governo militar, como "Cruzeiro Novo", mantendo-se em circulação até 1975. 
Figura 3

Grade, Rodri-

go Torres, 2011.

Recorte, colagem

e montagem de

cédulas, 104 x 84

$\mathrm{cm}$. Coleção Sérgio

Carvalho s.d.

Figura 4 Camafeu,

Rodrigo Torres, 2011

Recorte, colagem e montagem de cédulas

104 x 84 cm Coleção

Sérgio Carvalho s.d.
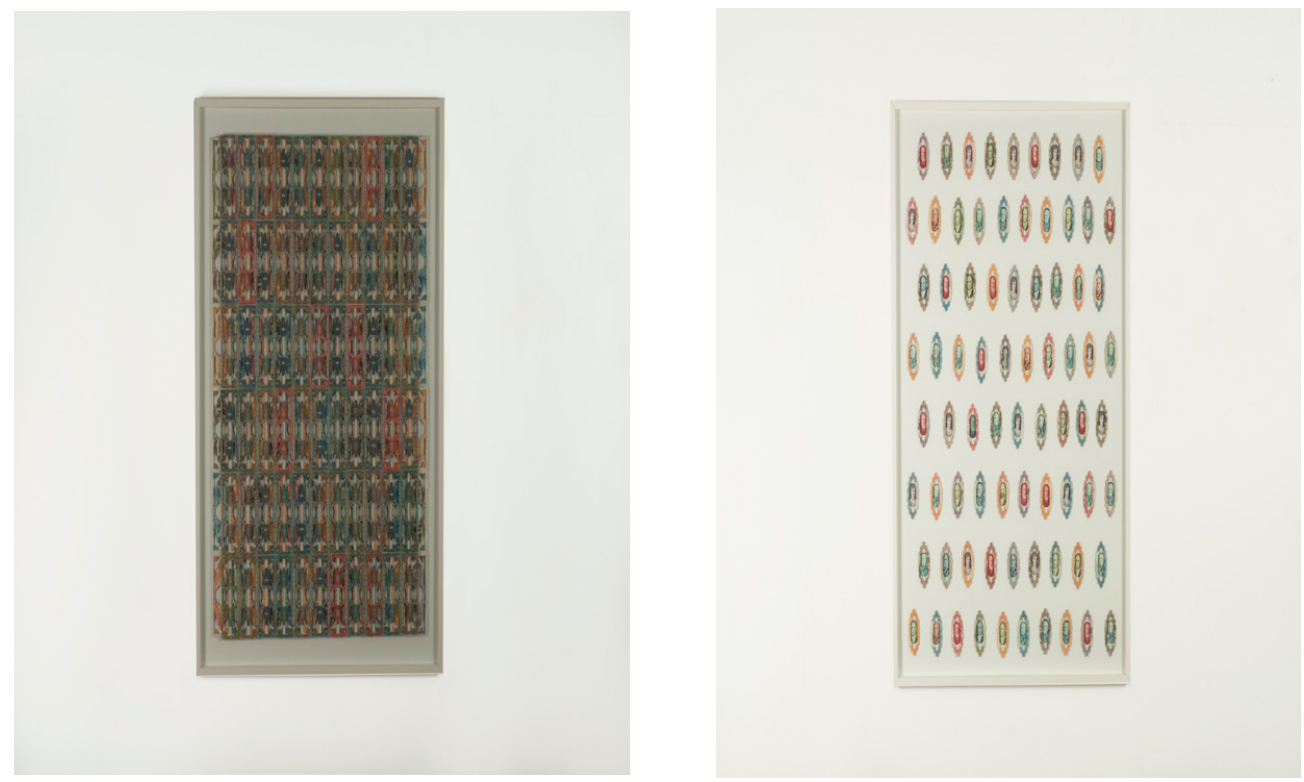

Essa série de notas trazia no seu anverso, além da imagem de Getúlio Vargas, na cédula de dez cruzeiros, uma série de personagens do império, Marques de Tamandaré ( $\operatorname{Cr} \$ 1,00)$, Duque de Caxias ( $\operatorname{Cr} \$ 2,00)$, Barão do Rio Branco ( $\mathrm{Cr} \$ 5,00)$, Manoel Deodoro da Fonseca $(\mathrm{Cr} \$ 20,00)$, Princesa Isabel (Cr\$50,00), D. Pedro II (Cr\$100,00), D. Pedro I (Cr\$200,00), D. João VI (Cr\$500,00), Pedro Álvares Cabral ( $C r \$ 1.000,00)$, Tiradentes $(\mathrm{Cr} \$ 5.000,00)$ e a única outra personalidade da república, Santos Dumont ( $\mathrm{Cr} \$ 10.000,00)$. Com exceção das duas últimas, de maior valor e que foram emitidas apenas a partir de 1963 e 1965, em decorrência já da inflação do período, a série possuía uma uniformidade na estrutura que possibilita ao artista a produção de um conjunto visualmente atraente.

Para além do aspecto visual, essa série possui certas particularidades que cabem ser mencionadas. A série foi instituída pelo Decreto-Lei $n^{\circ} 4.791$ em 5 de outubro de 1942. O decreto inicial autorizava a emissão de notas de 10, 20, 50, 100, 200, 500 e 1.000 cruzeiros. Getúlio Vargas, presidente à época, figurava na cédula de 10 cruzeiros, a cédula de menor valor e, portanto, a de maior circulação e visibilidade31. Em virtude da carestia de

31 FRAGA, André Barbosa. Os heróis da pátria: política cultural e história do Brasil no governo Vargas. 2012. Dissertação (Mestrado em História) - Instituto de Ciências Humanas e Filosofia, Universidade Federal Fluminense. Niterói, Rio de Janeiro, 2012, p. 20. Disponível em: /https://www.historia.uff.br/stricto/teses/Dissert-2012_Andre_ Barbosa_Fraga.pdf. Acesso em 17/11/2019. 
metais em decorrência da guerra, foi editado do Decreto-Lei n ${ }^{\circ} 4.842$ em 17 de outubro de 1942, que autorizou a circulação das cédulas de $\operatorname{Cr} \$ 5,00$ e o Decreto-Lei n 6.705 de 17 de julho de 1944 autorizando a emissão e circulação de cédulas de $\operatorname{Cr} \$ 1,00$ e $\operatorname{Cr} \$ 2,00$.

Essas cédulas de $\mathrm{Cr} \$ 1,00$ e $\mathrm{Cr} \$ 1.000,00$ foram as cédulas utilizadas por Cildo Meireles em 1969 no trabalho Árvore do Dinheiro, quando carimbadas com o valor de $\mathrm{Cr} \$ 1,00$.

Também faz parte dessa família de cédulas a eminente cédula de cinco cruzeiros, de terceira estampa. Emitida apenas a partir de 1961, foi a primeira cédula totalmente elaborada e confeccionada pela Casa da Moeda do Brasil, com projeto artístico 100\% relacionado à cultura brasileira. Curiosamente essa cédula ficou conhecida como a "Cédula do Índio", por estampar um índio em seu anverso. Esta cédula não foi utilizada no trabaIho em tela.

O políptico é formado por quatro obras, sendo duas de nome Grid e duas de nome Camafeu. As telas guardam grande semelhança duas a duas, sendo as primeiras obras, colagens com duas grades sobrepostas (com uma certa distância entre elas, dando mais uma vez o efeito de profundidade) geradas a partir das cédulas das quais foram retirados os bustos e alguns elementos decorativos, formado uma estrutura de grid. Vazio de poder, constam apenas os valores e as inscrições institucionais (REPÚBLICA DOS ESTADOS UNIDOS DO BRASIL, NO TESOURO NACIONAL, VALOR RECEBIDO, os valores numéricos e por extenso de cada cédula, além do nome da personalidade representada, sob uma moldura oval vazia). Na grade em primeiro plano as cédulas estão todas dispostas com o anverso disposto para o espectador num esquema de $11 \times 6$ cédulas. No segundo plano as cédulas apresentam seu reverso, onde se consegue ler por entre os recortes: ESTADOS UNIDOS DO BRASIL, REPÚBLICA DOS ESTADOS UNIDOS DO BRASIL e, em letras miúdas, AMERICAN BANK NOTE COMPANY, em um esquema de $12 \times 6$ cédulas.

O grid está organizado na obra de forma vertical, ou seja, as cédulas não estão afixadas com seus escritos na horizontal, mas sim na vertical, e eventualmente estão também colocadas umas ao contrário de outras. Esse pro- 
cedimento esvazia um pouco mais as cédulas, uma vez que as inscrições que restaram não são diretamente legíveis. O arranjo de planos de tamanho distinto causa um deslocamento entre eles (ambos estão centralizados na montagem final), produzindo um embaralhamento entre o primeiro e o segundo plano, aumentando a densidade da obra e contribuindo com a dificuldade de leitura, exigindo que o observador se aproxime dela para distinguir suas partes.

O grid está emoldurado sobre um fundo branco (os recortes possibilitam ver através da obra), o que destaca ainda mais o procedimento de esvaziamento das cédulas.

No segundo par de obras (as obras Camafeu) o artista se utiliza das partes removidas do primeiro e, fixando-as como um camafeu, articula um verdadeiro panteão da pátria. Cada obra conta com setenta e seis bustos, das seguintes personalidades: Marquês de Tamandaré, Duque de Caxias, Barão do Rio Branco, Getúlio Vargas, Deodoro da Fonseca, Princesa Isabel, D. Pedro II, D. João VI e Pedro Álvares Cabral. Esses bustos, estão repetidos diversas vezes e, aparentemente, sem uma ordem determinada.

Nota-se a ausência de D. Pedro I, presente na cédula de $\operatorname{Cr} \$ 200,00$, utilizada nas primeiras obras e ausente entre os personagens selecionados para o segundo par de obras.

Aqui, apesar de tamanho equivalente ao das obras Grade, a densidade da obra é significativamente menor. As efígies estão placidamente afixadas sob um fundo branco, juntamente com parte dos elementos decorativos removidos das cédulas, formando molduras. Não há tridimensionalidade alguma (apesar de, tradicionalmente, uma das características do camafeu seja a tridimensionalidade) e o espaço entre os bustos é generoso, colocando as figuras em destaque apesar de seu reduzido tamanho.

Oportunamente, verifiquemos a definição do verbete camafeu no Dicionário Houaiss da Língua Portuguesa em sua edição do ano de 2001:

Camafeu s.m. (1297 cf. IVPM) 1 Pedra delgada, ger. semipreciosa, que tem duas camadas de tonalidades diferentes da mesma cor (ou de cores diferentes), numa das quais se esculpe uma figura em alto-relevo, deixando-se à mostra a camada inferior; us. como ornamento, esp. do vestuário 2 p. ext. qualquer peça de pedra fina, talhada em relevo 3 p. ext. qualquer figura em relevo, como de sinete, efígie de moeda etc. 4 infrm. Mulher de rosto delicado 5 iron. Mulher ou homem muito feio e/ou deselegante 
Apesar da ironia ser incluída na definição de camafeu e essa abordagem ser comum na obra do artista, assim como a obras da coleção, partimos da ausência deste componente nessas obras, assumindo que a manobra se refere mais a um jogo de poder que a uma ironia quanto à representatividade das personalidades apresentadas no trabalho.

Entendemos que o arranjo final das obras da série Camafeu atribui poder às personalidades onde, ao contrário das primeiras, não parece haver qualquer intenção de esvaziamento, parece sim haver a intenção de se valorizar as figuras, de demonstrar o poder que aqueles vultos históricos já possuíram em suas mãos, mesmo apartados de um instrumento de poder.

Aqui o dinheiro assume uma ausência, não há que se falar em valor do dinheiro como mercadoria de troca (uma vez que esse se deteriorou ainda nos anos de 1960), mas de dinheiro como portador de um símbolo, de uma história que ele carrega como um símbolo de poder, esvaziado pelo artista, porém, gerando um novo altar, um novo panteão com as personalidades destacadas.

Se por um lado a remoção dessas personalidades constitui o esvaziamento do status dado pela figuração em uma cédula de dinheiro corrente, por outro a sua transposição para uma obra de arte contemporânea as eterniza como arte, trasladando-as para a contemporaneidade. Lado a lado com as cédulas recortadas, esvaziadas de valor monetário e do status de seus figurantes, essas personalidades passam para um novo sistema, reinventados e mais uma vez eternizados.

Os jovens artistas apresentam em suas obras visões e críticas de seu tempo, investigando e refletindo sobre questões que se colocam em suas realidades, assim como Cildo Meireles o fez no seu momento (e, obviamente, ainda o faz). A questão não se esgota. A organização social e a realidade brasileira suscitam uma discussão própria, cujas faces encontram-se, muitas vezes, guardadas em coleções particulares. O percurso apresentado e suas ramificações ainda não exploradas ressaltam a importância dessas coleções na preservação e disponibilização desse acervo para consulta e pesquisa. A História da Arte no Brasil vai se construindo com o apoio desses agentes, promovendo a circulação, o acesso e as diversas leituras dos seus acervos. 